SUPPORTING INFORMATION

\title{
Effects of Multidentate Metal Interactions on the Structure of \\ Collisionally Activated Proteins: Insights from Ion Mobility \\ Spectrometry and Molecular Dynamics Simulations
}

\author{
Claire E. Bartman, Haidy Metwally, and Lars Konermann* \\ Department of Chemistry, The University of Western Ontario, London, Ontario, N6A 5B7, Canada
}

This file contains:

Extended Methods Section: Experimental procedures and MD simulation details.

Supporting Figure S1: CIU profiles of all three proteins for various metalation levels.

Supporting Figure S2: CIU profiles of $\mathrm{Cyt}^{7+}$ for various metalation levels.

Supporting Figure S3: Summary of MD structures. 
Mass Spectrometry and Ion Mobility Spectrometry. Measurements on Ubq (8565 Da), Cyt (12359 Da), and hMb (17568 Da) were conducted on a Synapt G1 HDMS time-of-flight mass spectrometer (Waters, Milford, MA). The total acetate concentration in the various experiments was virtually the same, i.e., $10.1 \mathrm{mM}$ for metal-containing solutions vs $10.0 \mathrm{mM}$ for metal-free samples. This implies that none of the salt-induced effects discussed in the main text are attributable to anion-mediated factors. Protein solutions were infused into the instrument's Z-spray ESI source at $5 \mu \mathrm{L} \mathrm{min}{ }^{-1}$. The experiments were conducted at a capillary voltage of $2.8 \mathrm{kV}$ with the extraction cone set to $1 \mathrm{~V}$. The cone gas flow rate was $50 \mathrm{~L} \mathrm{~h}^{-1}$, and the desolvation gas flow rate was $500 \mathrm{~L} \mathrm{~h}^{-1}$, while the source and desolvation temperatures were kept at $25{ }^{\circ} \mathrm{C}$ and $40{ }^{\circ} \mathrm{C}$. Other experimental parameters included a trap collision energy of $2 \mathrm{~V}$, trap wave velocity of 100 $\mathrm{m} \mathrm{s}^{-1}$, trap wave height of $0.3 \mathrm{~V}$, and trap bias of $9 \mathrm{~V}$. The IMS wave height was $6.5 \mathrm{~V}$ at $300 \mathrm{~m} \mathrm{~s}^{-}$ ${ }^{1}$. The transfer collision energy was $4 \mathrm{~V}$ at $247 \mathrm{~m} \mathrm{~s}^{-1}$, and the transfer wave height was $4 \mathrm{~V}$. The trap entrance was set to $1 \mathrm{~V}$, IMS entrance $6.7 \mathrm{~V}$, IMS exit $0 \mathrm{~V}$, transfer entrance $1 \mathrm{~V}$, and transfer exit $1 \mathrm{~V}$. Collisional heating was conducted by exposing the electrosprayed proteins to different cone voltages covering the range between $5 \mathrm{~V}$ and $135 \mathrm{~V} . \mathrm{Na}^{+}$or $\mathrm{Ca}^{2+}$ loss during collisional activation is negligible under these conditions. ${ }^{1}$ Traveling-wave IMS calibration was performed as described, using a denatured protein mix consisting of $10 \mu \mathrm{M}$ Ubq, Cyt, and apo-myoglobin in 49:49:2 (v/v/v) methanol/water/acetic. ${ }^{2}$ The use of reference data measured on He drift tube instruments implies that the $\Omega$ distributions reported here represent effective He collision cross sections, although our experiments employed $\mathrm{N}_{2}$ as buffer gas. ${ }^{3,4}$ None of the mass spectra or IMS distributions shown in this work was subjected to data smoothing. In some instances it is beneficial to characterize $\Omega$ distributions in terms of a single averaged collision cross section, $\Omega_{\mathrm{av}}$, calculated as 


$$
\Omega_{a v}=\frac{\int I(\Omega) \Omega d \Omega}{\int I(\Omega) d \Omega}
$$

where $I(\Omega)$ is the intensity profile of the $\Omega$ distribution.

Molecular Dynamics Simulations. MD simulations were performed on Ubq in the gas phase. The $\mathrm{X}$-ray structure $1 \mathrm{UBQ}^{5}$ served as starting point. MD runs were conducted with GPU acceleration using GROMACS 5.1 for leap frog integration of Newton's equations, with the a time step of $1 \mathrm{fs}{ }^{6}$ The CHARMM36 all-atom force field ${ }^{7}$ was chosen because of its proven track record for Ubq simulations, both in an ESI context ${ }^{8}$ and in bulk solution. ${ }^{9}$ Electrostatic and van der Waals interactions were modeled without cut-offs. To match the experimental conditions, all runs were conducted with a $6+$ net protein charge. Side chain protonation patterns were set using PDB2GMX. All runs started with a steepest descent energy minimization. Unless noted otherwise, titratable sites were used with their default charges, i.e., N-terminus ${ }^{+}, \mathrm{Arg}^{+}, \mathrm{Lys}^{+}, \mathrm{His}^{0}, \mathrm{Glu}^{-}, \mathrm{Asp}^{-}$, and C-terminus`. The canonical charge of Ubq in neutral solution is zero, resulting from equal numbers of protonated groups (N-terminus $\left.{ }^{+}, 4 \mathrm{Arg}^{+}, 7 \mathrm{Lys}^{+}\right)$and deprotonated moieties (6 $\mathrm{Glu}^{-}, 5 \mathrm{Asp}^{-}$, C-terminus $)$. In metal-free solution some of the carboxylates will undergo protonation during the final stages of ESI, thereby imparting the protein with its net $6+$ charge. $^{8}$ For modeling $[\mathrm{Ubq}+6 \mathrm{H}]^{6+}$ we chose to protonate the six Glu residues, keeping in mind that Glu is more basic than Asp ${ }^{-10}$ All other residues were in their default titration states.

Metal-bound starting structures were generated by temporarily giving the protein a negative net charge via neutralization of all Lys side chains. Six $\mathrm{Na}^{+}$or three $\mathrm{Ca}^{2+}$ were then placed in random positions $\sim 0.5 \mathrm{~nm}$ away from the protein surface. This was followed by equilibration at $20 \mathrm{~K}$ for $1 \mathrm{~ns}$, during which the metal ions attached to the protein. Subsequently, the side chain charges were 
reverted to their default values, thereby ensuring a $6+$ net protein charge for all subsequent steps. Production runs were conducted over a 100 ns period, during which the temperature was ramped linearly from $350 \mathrm{~K}$ to $1000 \mathrm{~K}$. This temperature range is comparable to that used for previous CIU simulations. ${ }^{11-13}$ Similar to those earlier studies ${ }^{11-13}$ our simulations did not involve an explicit collision gas. Instead, temperature control was achieved by employing a Nosé-Hoover thermostat ${ }^{14}$ with a relaxation constant of 0.5 ps. All MD runs were repeated five times with different initial metalation patterns and atom starting velocities that were sampled at random from a MaxwellBoltzmann distribution. 

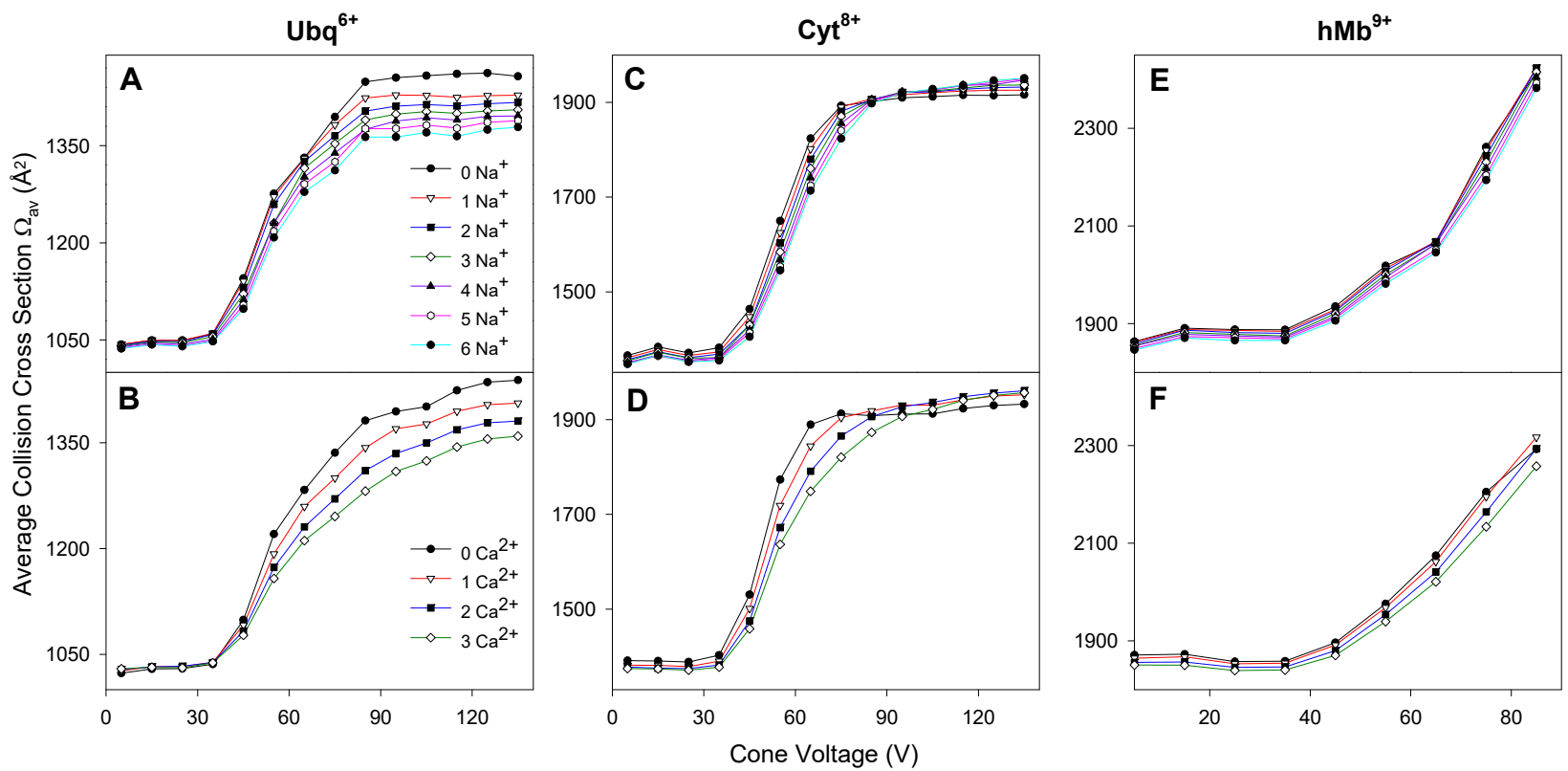

Supporting Figure S1. CIU profiles of $\mathrm{Ubq}^{6+}(\mathrm{A}, \mathrm{B}), \mathrm{Cyt}^{8+}(\mathrm{C}, \mathrm{D})$, and $\mathrm{hMb}^{9+}(\mathrm{E}, \mathrm{F})$. Proteins in the first row were electrosprayed in the presence of sodium acetate, the profiles represent ions bound to $0,1, \ldots, 6 \mathrm{Na}^{+}$. Proteins in the second row were electrosprayed in the presence of calcium acetate, the profiles represent ions bound to $0,1,2,3 \mathrm{Ca}^{2+} . \Omega_{\mathrm{av}}$ values were calculated using eq. 1. Metaldependent differences are highly prevalent for Ubq, where each additional metal ion shifts the CIU profile to markedly lower $\Omega(\mathrm{A}, \mathrm{B})$. Qualitatively similar effects are seen for Cyt, although for cone voltages beyond $85 \mathrm{~V}$ the metal-free protein levels off at slightly lower $\Omega$ than the adducted species (C, D). Progressive compaction with increasing metalation is also apparent for collisionally activated $\mathrm{hMb}$, particularly in the case of $\mathrm{Ca}^{2+}$ adduction $(\mathrm{F})$. 


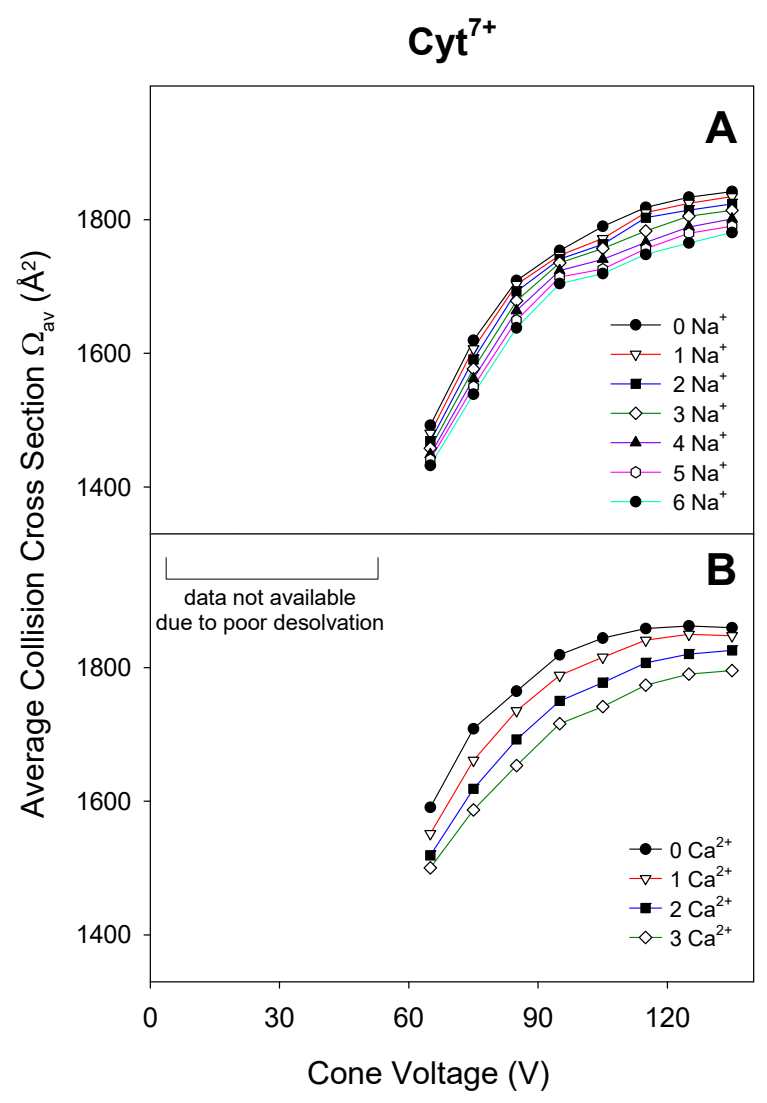

Supporting Figure S2. CIU profiles of $\mathrm{Cyt}^{7+}$. (A) Data acquired in the presence of sodium acetate; the profiles correspond to ions carrying $0,1, \ldots, 6 \mathrm{Na}^{+}$. (B) Data acquired in the presence of calcium acetate; the profiles represent ions bound to $0,1,2,3 \mathrm{Ca}^{2+}$. The profiles shown here reveal the same trends as in Figure S1, i.e., under CIU conditions proteins that bind more metal ions are more compact. Poor desolvation characteristics of $\mathrm{Cyt}^{7+}$ preclude the analysis of data for cone voltages below $65 \mathrm{~V}$. This is in contrast to $\mathrm{Cyt}^{8+}$ (Figure S1), where data could be analyzed down to a cone voltage of $5 \mathrm{~V}$. Similarly, for Ubq and $\mathrm{hMb}$ low signal intensities precluded analyses of charge states other than $6+$ and 9+, respectively (cf. Figure 1A, C). 


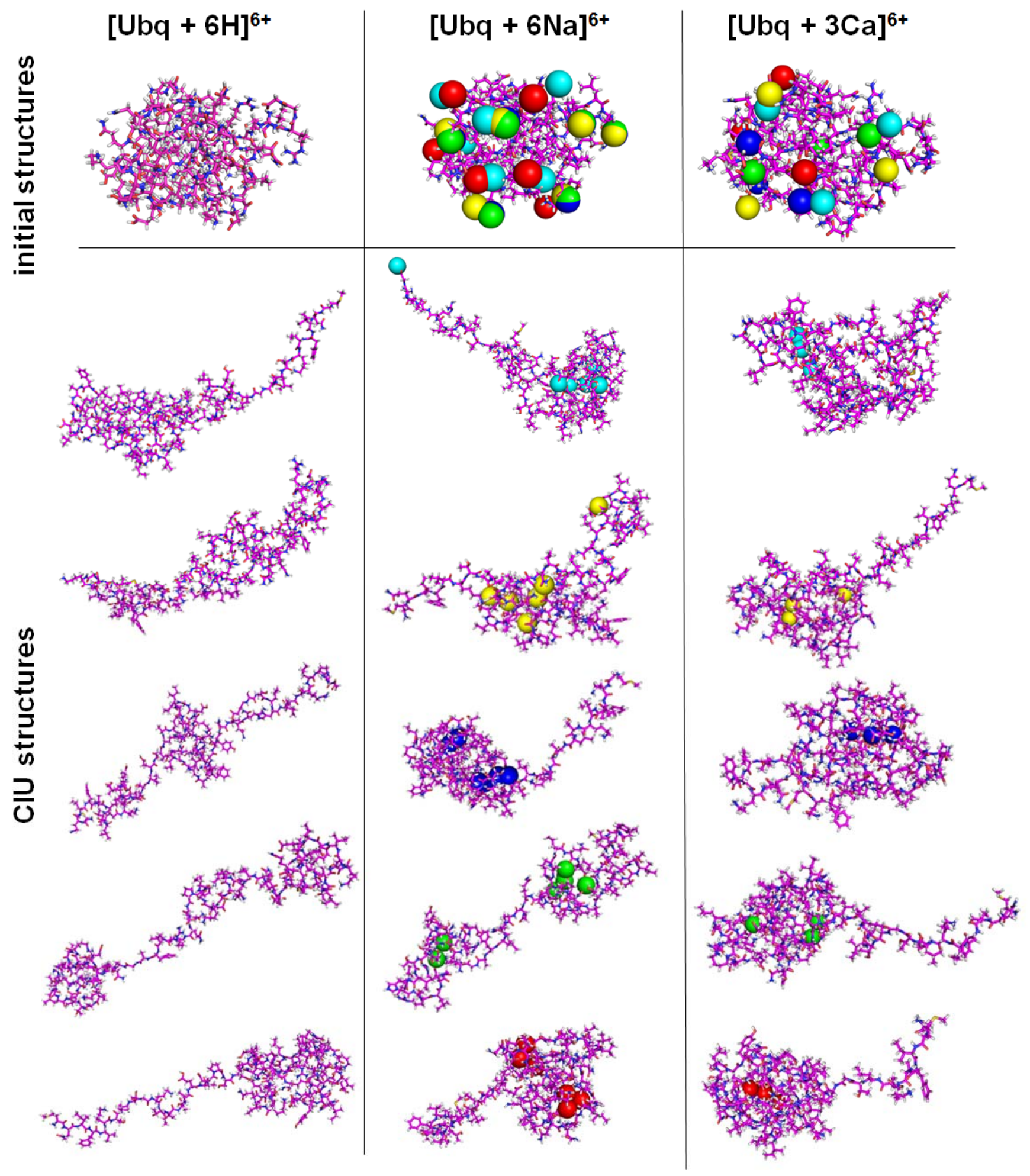

Supporting Figure S3. Top row: Equilibrated $T=20 \mathrm{~K}$ starting conformations for CIU simulations on $[\mathrm{Ubq}+6 \mathrm{H}]^{6+}$, $[\mathrm{Ubq}+6 \mathrm{Na}]^{6+}$, and $[\mathrm{Ubq}+3 \mathrm{Ca}]^{6+}$. For the adducted forms the binding sites of all metal ions are shown superimposed on a single protein structure. The bottom of the figure illustrates the final CIU structures $(t=100 \mathrm{~ns}, T=1000 \mathrm{~K})$ for each run. 


\section{SI References}

(1) Verkerk, U. H.; Kebarle, P. J. Am. Soc. Mass Spectrom. 2005, 16, 1325-1341.

(2) Sun, Y.; Vahidi, S.; Sowole, M. A.; Konermann, L. J. Am. Soc. Mass Spectrom. 2016, 27, 31-40.

(3) Bush, M. F.; Hall, Z.; Giles, K.; Hoyes, J.; Robinson, C. V.; Ruotolo, B. T. Anal. Chem. 2010, 82, 9667-9565.

(4) Jurneczko, E.; Kalapothakis, J.; Campuzano, I. D. G.; Morris, M.; Barran, P. E. Anal. Chem. 2012, 84, 8524-8531.

(5) Vijay-Kumar, S.; Bugg, C. E.; Cook, W. J. J. Mol. Biol. 1987, 194, 531-544.

(6) Hess, B.; Kutzner, C.; van der Spoel, D.; Lindahl, E. J. Chem. Theory Comput. 2008, 4, 435-447.

(7) Huang, J.; MacKerell, A. D. J. Comput. Chem. 2013, 34, 2135-2145.

(8) McAllister, R. G.; Metwally, H.; Sun, Y.; Konermann, L. J. Am. Chem. Soc. 2015, 137, 12667-12676.

(9) Piana, S.; Lindorff-Larsen, K.; Shaw, D. E. Proc. Natl. Acad. Sci. U.S.A. 2013, 110, 59155920.

(10) Creighton, T. E. Proteins; W. H. Freeman \& Co: New York, 1993.

(11) Fegan, S. K.; Thachuk, M. J. Chem. Theory Comput. 2013, 9, 2531-2539.

(12) Hall, Z.; Politis, A.; Bush, M. F.; Smith, L. J.; Robinson, C. V. J. Am. Chem. Soc. 2012, 134, 3429-3438.

(13) Chen, S.-H.; Russell, D. H. J. Am. Soc. Mass Spectrom. 2015, 26, 1433-1443.

(14) Hoover, W. G. Phys. Rev. A 1985, 31, 1695-1697. 